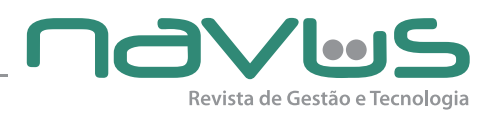

\title{
Uma visão do VI Congresso Brasileiro de Gerenciamento de Projetos
}

Helio Aisenberg Ferenhof ${ }^{1}$

\author{
1 REFERÊNCIA
}

CONGRESSO BRASILEIRO DE GERENCIAMENTO DE PROJETOS, 6., 2011, Ceará. Anais... Ceará: PMI-CE, 2011.

\section{CREDENCIAIS DO AUTOR}

Este trabalho tem como objetivo apresentar uma visão geral dos temas e estudos apresentados no VI CONGRESSO BRASILEIRO DE GERENCIAMENTO DE PROJETOS, realizado de 3 a 5 de novembro de 2011 na cidade de Fortaleza, Ceará. 0 evento foi organizado pelo Capítulo do Ceará do Project Management Institute (PMICE), uma rede internacional de profissionais de gerenciamento de projetos, objetivando: promover a difusão do gerenciamento de projetos; integrar profissionais, organizações públicas e empresas privadas, com e sem fins lucrativos, em torno do gerenciamento de projetos; estimular a integração entre filiados de um mesmo Capítulo; valorizar profissionais de destaque na condução de projetos, programas e portfólios; estimular o contato de forma inovadora entre filiados de diferentes Capítulos; divulgação nacional e internacional do PMI e do Congresso Brasileiro.

\section{RESUMO}

O evento foi organizado em três dias com tipos de sessões distintas: o primeiro dia destinado ao III FÓRUM INTERNACIONAL DE GOVERNO, onde foi dado o enfoque ao que a gestão de projetos pode contribuir com o primeiro setor. 0 segundo dia se destinou a palestras de profissionais da área, que enfocaram na capacitação em gerenciamento de projetos, nos grupos de processos apontados pelo $\mathrm{PMBOK}^{\circledR} \mathrm{e}$, em metodologias propostas para fazer gestão de projetos; 0 terceiro e último dia foi destinado à apresentação de artigos científicos ganhadores do prêmio Visconde de Mauá pela comunidade acadêmica.

As sessões destinadas ao primeiro setor foram divididas em quatro salas e ocorreram em paralelo. A sala principal foi destinada às palestras e debates e nas demais salas, oficinas, cursos e workshops, respectivamente.

O foco do fórum circulou sobre estratégias, planejamento em projetos, gestão dos recursos humanos na gestão pública e a implantação de um escritório de projetos, Project Management Office (PMO) e seus desafios.

1 Graduado em Ciência da Computação pela Universidade Estácio de Sá (1999). MBAE-Bussiness pela FGV-RJ,(2001) Mestre em Gestão do Conhecimento do PPGEGC/UFSC (2011).Atualmenteédoutorandona Engenharia da Produção(UFSC) eorientadorda Pós-GraduaçãodoSENAC/SC, e-mail:helio@igci.com.br. 


\section{APRECIAÇÃO CRÍTICA DO RESENHISTA}

Observou-se um especial interesse no debate acerca do uso e aplicabilidade dos conceitos, ferramentas e técnicas de gerenciamento de projetos para auxiliar a administração pública a atingir suas metas, bem como dar subsídios para o governo estar de acordo com os princípios da administração pública, previstos no Artigo 37 da Constituição Federal.

A oficina focalizou na gestão pública por intermédio do gerenciamento do valor agregado. Dada a importância do tema, a oficina teve quatro horas de duração.

O conceito de valor está diretamente associado a pessoa que está a valorar, ou seja, aquele que percebe o valor de algo. Sendo assim, muito subjetivo, pois esta percepção é pessoal e ainda temporal. Uma vez que não é estática, o sujeito pode mudar de conceito, ideia, interesses e prioridades. 0 valor sobre algo pode ser altamente elevado por um grupo de stakeholders e, ao mesmo tempo, pode ser desvalorizado por outros. Não existe uma receita simples para sua criação.

Devido a esse fato, destaca-se a necessidade da gestão dos stakeholders, indicada pelo PMBOK como de suma importância. A administração pública só tem a ganhar ao fazer a gestão dos stakeholders, pois ao planejar as ações a serem tomadas, terá condições de entregar um produto do projeto adequado às expectativas destes.

Nos workshops houve destaque para a criação de PMO, com duração de duas horas, e uma dinâmica com foco no planejamento, execução e controle de obras, também com duas horas de duração, ressaltando a importância da gestão de projetos.

Em momentos houve palestras simultâneas dos mais diversos assuntos relacionados ao gerenciamento de projetos, desde gestão dos stakeholders, competências, capacitação, gestão de mudanças, criação de PMO e metodologias para gestão de projetos. Em outros momentos, houve a junção do grande grupo, como na palestra do astronauta brasileiro, Marcos Pontes, intitulada "Rumo ao Sucesso! O gerenciamento de projetos aplicado a sua vida." Marcos fez uma breve explanação de seu projeto de vida, desde quando era menino até se tornar o primeiro astronauta brasileiro e conhecer o espaço. Foi uma palestra motivacional associada a definições de escopo, metas e gestão de riscos.

As palestras contribuíram, e muito, com os profissionais da área de gerenciamento de projetos nas mais diversas áreas de conhecimento, demonstrando habilidades e técnicas necessárias para a gestão de projetos.

Para o fechamento do evento, o último dia se destinou à transferência de conhecimentos da academia para o público em geral. 0 objetivo do Prêmio é destacar o desenvolvimento científico em Gerenciamento de Projetos, valorizando os trabalhos de pós-graduação aprovados por Instituições de Ensino Superior (IES) de todo o Brasil, públicas ou privadas. Foram cinco artigos ganhadores do prêmio, sendo um relacionado à percepção de valores de liderança dos gerentes de projetos; dois relacionados à gestão de riscos, e os dois últimos, relacionados à gestão do conhecimento na gestão de projetos.

A academia contribuiu brilhantemente com palestras que trouxeram a união da visão mais metodológica à aplicação prática em empresas dos mais diversos setores, aproximando ainda mais o mercado das universidades.

O congresso ajudou a desmistificar a gestão de projetos em todos os setores da economia, tendo no primeiro dia como foco, o primeiro setor, e nos demais dias, todos os setores. 0 mesmo apontou a importância de se utilizar uma metodologia para a gestão de projetos, bem como a necessidade de conhecer as melhores práticas de gestão de projetos apontadas pelo PMBOK ${ }^{\circledR}$.

Além da visão de melhores práticas de projetos, foi reforçada em diversas palestras a necessidade de se adotar uma metodologia para fazer a gestão de projetos. Foram abordadas a metodologia ágil Scrum ${ }^{\circledR}$, MétodoWare ${ }^{\circledR}$, BasicMetodoWare ${ }^{\circledR}$ e Prince $2^{\circledR}$, ampliando os horizontes dos gestores rumo à eficácia e eficiência da gestão. 